\title{
Scopus-Based Analysis of Solar Energy Research in the United Arab Emirates
}

\author{
Omar Akash* \\ RAK Research \& Innovation Center, American University of Ras Al Khaimah, United Arab Emirates
}

\begin{abstract}
This paper examines and presents the solar energy research situation in the UAE using Scopus-database. Like other countries of GCC, the UAE realizes that it has to rely less on oil and gas and start to consider other sources of energy for power production. The country began to support scientific research to be conducted in alternative energy resources such as solar energy since the early Nineties. However, it was very limited. More research was conducted at somewhat larger scale during the past 10 years. Many researchers worked on various applications of solar energy for electricity production, water desalination, space cooling, etc. This work can be used by researchers, politicians, industry, or decision makers to see how much the UAE invested in the field of solar energy and how it compares to other countries in the GCC, Arab world, and worldwide. It presents and identifies those active institutions and researchers in the field of solar energy in the UAE using the data collected by Scopus. The progress of solar energy research in the UAE is also presented.
\end{abstract}

Keywords: Solar energy, Scopus, UAE

\section{Introduction}

UAE is considered as one of the highest countries in the world in terms of carbon emissions per capita, efforts, resources and time is now being invested in finding ways to reduce this high percentage of energy consumption in order to account for a more environment-friendly utilities by taking advantage of the different methods that is used around the globe, also a big effort on research and development of these technologies is being took into consideration. In this paper a light will be shed on what progress has been achieved in or with cooperation with UAE regarding different technologies like photovoltaic panels, Hybrid grid systems, wind energy, solar cooling, hydrogen energy and green buildings, also the progress in measuring the solar radiation throughout the year in different research institutions will be discussed. The attribution of different institutions, researchers and scientific journals in the field of solar energy in UAE based on Scopus data base will also be discussed.

\section{Discussion}

\subsection{UAE Research Situation in Measuring Solar Radiation}

Many studies conducted through GCC countries accounts for measuring the solar global, direct and beam radiation [1]. Measured global and diffuse solar radiation on horizontal and tilted surfaces in Jeddah, Saudi Arabia, the obtained values from this experiment were used to develop correlations to compute the diffuse radiation, Abdalla and Baghdady [2] have measured global and diffuse solar radiation in Doha, they used two different methods of estimating the diffuse radiation and both of them showed almost same results. Khalil and Alnajjar [3] measured the global and the diffuse radiation in UAE and compared the experimental results with the theoretical results. This study stated the high potential of solar radiation for UAE. Islam [4] conducted a study in Abu Dhabi to measure the direct beam radiation for one year, the research states that the mean direct beam solar radiation is more than $400 \mathrm{~W} / \mathrm{m}^{2}$ for the whole year, the study also show that the direct beam radiation is at its highest value in April, May and June.

${ }^{*}$ Corresponding author

E-mail: omar.akash@aurak.ac.ae

(C) 2016 International Association for Sharing Knowledge and Sustainability

DOI: $10.5383 /$ ijtee. 12.02 .005 


\subsection{UAE Research Situation in Wind Energy}

Wind speed data was collected for Abu Dhabi by the Petroleum Institute. The study stated that higher wind speeds can be used from April to October, during this period of time the maximum speed recorded through this study was $13 \mathrm{~km} /$ hour. An 18 months study [5] conducted in al Fujairah Department of Industry indicated that the wind energy capacity ranges between $130 \mathrm{MW}$ and $200 \mathrm{MW}$ in Dhadnah Masafi. Ouarda [6] has used the probability density functions which are used to identify the wind speed distributions. In this study the wind speed was recorded in 9 different stations in UAE, a selection of the probability density functions are used to model hourly wind speed data recorded at 9 stations in the United Arab Emirates. Models used include parametric models, mixture models and one non-parametric model using the kernel density concept. A detailed comparison between these three approaches [6].

\subsection{UAE Research Situation in Green Buildings}

An interesting research that talks about different green buildings regulations and codes in Arab countries in general and in Qatar, UAE and Lebanon in specific [7], it also shed a light on what are the different challenges and constrains that faces the development and the implementation of the green building in these countries, this article shows how the Arab countries still have a long way in order that they reach their goals and visions towards a more environmental friendly buildings however, it also shows how a tremendous work is being done on both the governmental and the private sectors. Another interesting research for developing countries in general and for Jordan in specific by Ali and Nsairat [8], this research focus on different international green building assessment tools such as such as LEED, CASBEE, BREEAM, GB Tool, and others, another outcome of this research was a computer based tool that matches the environmental conditions in Jordan for developing the implementations of green buildings. Another project held in RAKRIC [9] the main idea of this project was to test different insulation materials using the exact same conditions in terms of the size of the rooms as shown in Figure 1, the AC size used and using the same location. Radhi [10] focused on buildings in Bahrain with internal load dominated and does regression analysis on the existing building.

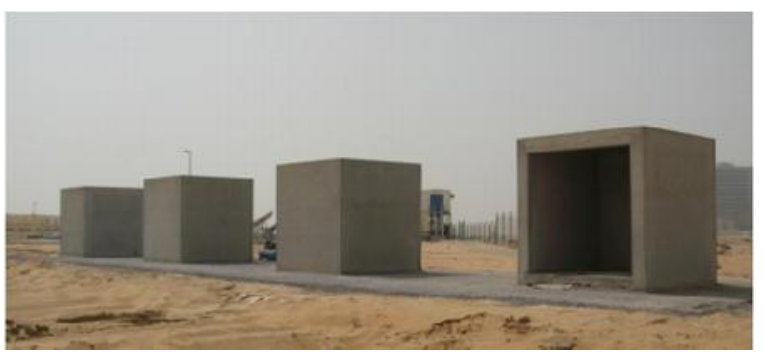

Figure 1. Solar Calorimeter installed at RAKRIC, UAE

\subsection{UAE Research Situation in Hybrid Grid Systems}

The findings of Nour and Rohani [11], aims for studying the feasibility of connecting a stand-alone PV-diesel hybrid power system for a village located in in the western region of $\mathrm{Abu}$ Dhabi in UAE, the research presents how a conventional power source such as a diesel generator can be used to support a solar based power system to compensate in case of any power shortage from the solar system, the system is first simulated using HOMER software in order to check for the feasibility of the system's configuration and to check whether it can meet the electrical demand of the system or not. Another research that was implemented in RAKRIC [12, 13], as shown in Figure 2. The study shows how prior to connecting the stand alone system with the mini grid the power produced in one center was either consumed there or wasted, and how after implementing the mini grid these grids are effecting in a positive manner on the overall energy bill.

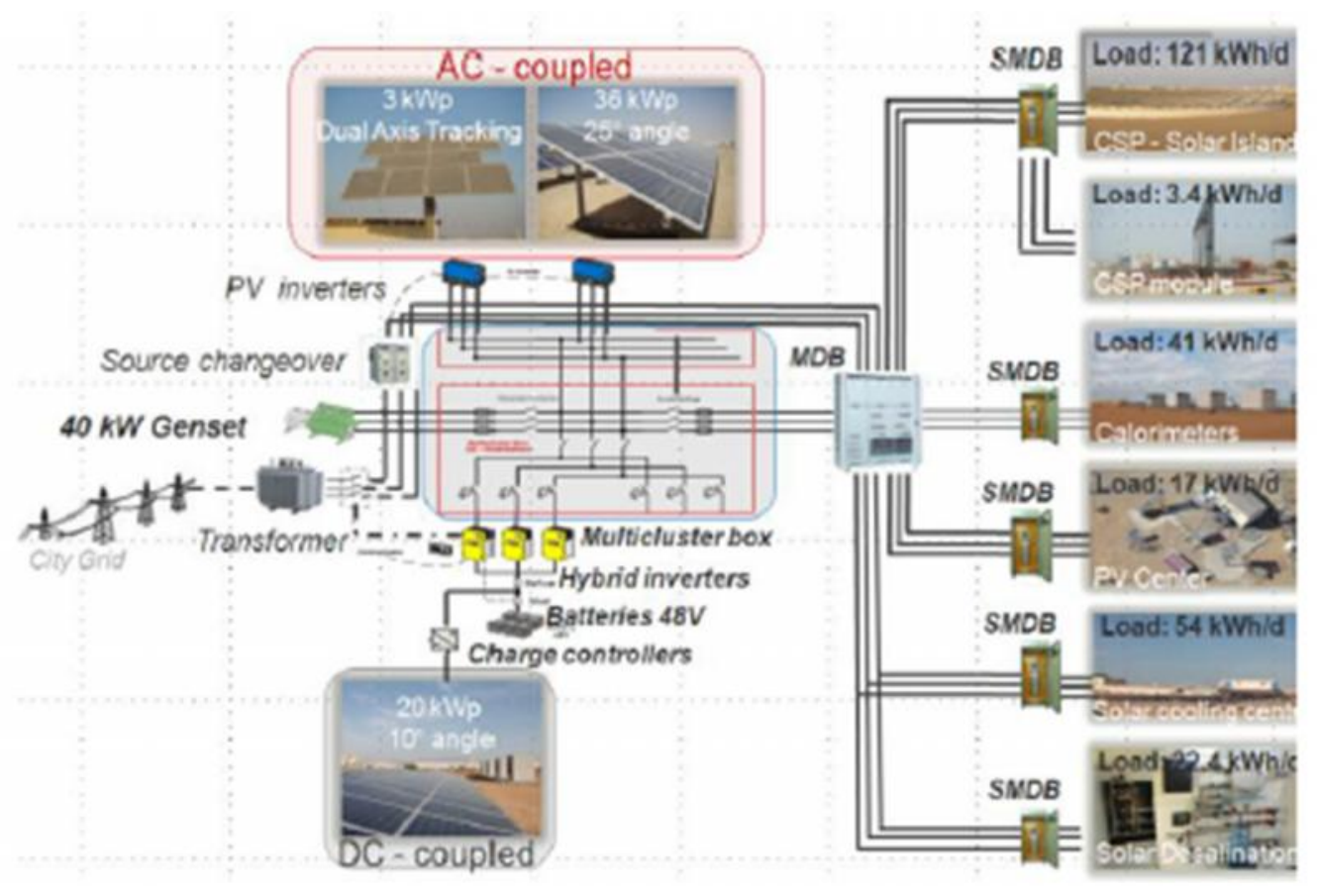

Figure 2. Line Diagram of Mingrid System 
Table 1. Top 10 Cited Solar-Related Articles from the UAE Based on Scopus Database

\begin{tabular}{|c|c|c|c|c|}
\hline SCR & $\begin{array}{l}\text { Authors } \\
\text { (Year of Publication) }\end{array}$ & Title & Journal name & $\begin{array}{l}\text { Times } \\
\text { cited }\end{array}$ \\
\hline $1^{\text {st }}$ & $\begin{array}{l}\text { Kraemer, D. } \\
\text { (2011) }\end{array}$ & $\begin{array}{l}\text { High performance flat-panel solar thermoelectric } \\
\text { generators with thermal concentration }\end{array}$ & Nature materials & 210 \\
\hline $2^{\text {nd }}$ & $\begin{array}{l}\text { Yoong, L.S. } \\
\text { (2009) }\end{array}$ & $\begin{array}{l}\text { development of copper-doped } \mathrm{TiO} 2 \text { photo-catalyst } \\
\text { for hydrogen production under visible light }\end{array}$ & Energy & 135 \\
\hline $3^{\text {rd }}$ & $\begin{array}{l}\text { Al Nabulsi, A. } \\
\text { (2012) }\end{array}$ & $\begin{array}{l}\text { Efficiency optimization of a dsp-based standalone } \\
\text { PV system using fuzzy logic and dual-MPPT } \\
\text { control }\end{array}$ & $\begin{array}{l}\text { IEEE Transactions } \\
\text { on Industrial } \\
\text { Informatics }\end{array}$ & 63 \\
\hline $4^{\text {th }}$ & $\begin{array}{l}\text { El Chaar, L. } \\
\text { (2011) }\end{array}$ & Review of photovoltaic technologies & $\begin{array}{l}\text { Renewable and } \\
\text { Sustainable Energy } \\
\text { Reviews }\end{array}$ & 62 \\
\hline $5^{\text {th }}$ & $\begin{array}{l}\text { Pohekar, S.D. } \\
(2005)\end{array}$ & $\begin{array}{l}\text { Dissemination of cooking energy alternatives in } \\
\text { India-A review }\end{array}$ & $\begin{array}{l}\text { Renewable and } \\
\text { Sustainable Energy } \\
\text { Reviews }\end{array}$ & 56 \\
\hline $6^{\text {th }}$ & $\begin{array}{l}\text { Martin-Puertas, C. } \\
\text { (2012) }\end{array}$ & $\begin{array}{l}\text { Regional atmospheric circulation shifts by a grand } \\
\text { solar minimum }\end{array}$ & Nature Geoscience & 47 \\
\hline $7^{\text {th }}$ & $\begin{array}{l}\text { Islam, M.D. } \\
\text { (2009) }\end{array}$ & $\begin{array}{l}\text { Measurement of solar energy radiation in Abu } \\
\text { Dhabi, UAE }\end{array}$ & Applied Energy & 40 \\
\hline $8^{\text {th }}$ & $\begin{array}{l}\text { Prantzos, N. } \\
\text { (2011) }\end{array}$ & $\begin{array}{l}\text { The } 511 \mathrm{Kev} \text { emission from positron annihilation } \\
\text { in the Galaxy }\end{array}$ & $\begin{array}{l}\text { Reviews of Modern } \\
\text { Physics }\end{array}$ & 39 \\
\hline $9^{\text {th }}$ & $\begin{array}{l}\text { Saffarini, R.B } \\
\text { (2012) }\end{array}$ & $\begin{array}{l}\text { Technical evaluation of stand-alone solar powered } \\
\text { membrane distillation systems }\end{array}$ & Desalination & 38 \\
\hline $10^{\text {th }}$ & $\begin{array}{l}\text { Helal, A.M, } \\
(2008)\end{array}$ & $\begin{array}{l}\text { Economic feasibility of alternative designs of a } \\
\text { PV-RO desalination unit for remote areas in the } \\
\text { United Arab Emirates }\end{array}$ & Desalination & 38 \\
\hline
\end{tabular}

SCR: standard competition ranking.

Table 1 shows the top 10 cited solar-related articles from the UAE based on Scopus database, the top cited article is High performance flat-panel solar thermoelectric generators with thermal concentration by Kraemer, D. it was cited 210 times. This table shows that the solar research in UAE is still in progress and further effort must be conducted in different educational and research institutions, and more funds have to be applied to carry on with the targets set by decision makers in the UAE.

Table 2 shows the Top six productive institutions from UAE or Collaborated with UAE during study period in terms of articles related to "solar" released (according to Scopus data base). The table states that Masdar institute of science and technology is the leading institute in UAE with 156 published articles, followed by United Arab Emirates University with 71 published articles during the time of the study.

Table 3 shows The top 5 countries world-wide in terms of their attribution in articles related to "solar" based on Scopus database, in the leading comes the USA with 98,838 articles published during the time that the study took place in, followed by China and then Germany with 36,721 and 27,462 articles respectively. Table 4 shows the top Arab countries in terms of their attribution in articles related to "solar" based on Scopus data base, in the leading comes Saudi Arabia with 1,820 articles published during the time that the study took place in, followed by Egypt and then Algeria with 1,766 and 1,132 articles respectively. UAE stands at the sixth position among Arab countries.

Table 2. Top Six Productive Institutions in the UAE

\begin{tabular}{llc}
\hline SCR & Affiliation & $\begin{array}{c}\text { Number of } \\
\text { documents }\end{array}$ \\
\hline 1 & Masdar Institute of Science \& Technology & 156 \\
2 & United Arab Emirates University & 71 \\
3 & The Petroleum Institute Abu Dhabi & 67 \\
4 & American University of Sharjah & 28 \\
5 & Khalifa University & 23 \\
6 & University of Sharjah & 21 \\
\hline
\end{tabular}




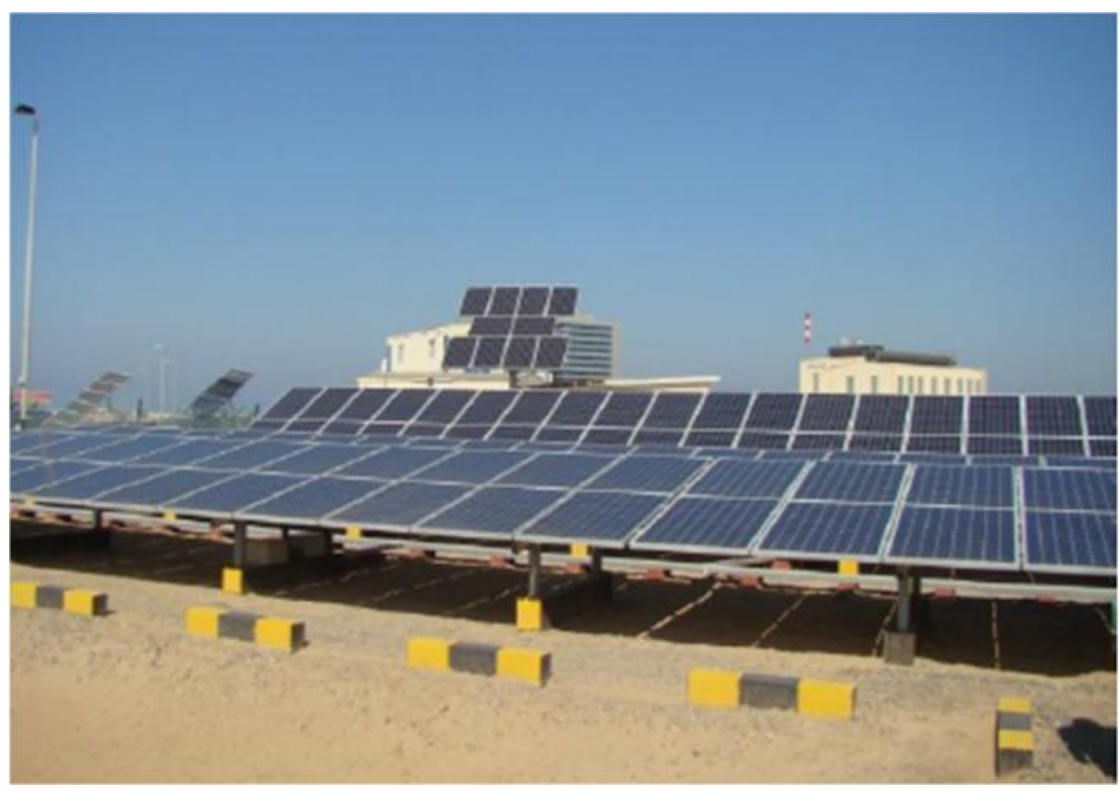

Figure 3. Installation of $59 \mathrm{kWe}$ PV System at RAKRIC, UAE

Table 3. Top Five Countries World-Wide in Terms of their Attribution in Articles Related to "Solar" on Scopus Database

\begin{tabular}{|c|c|c|c|c|c|c|c|c|}
\hline Country & $\begin{array}{c}\text { 2011- } \\
\text { Present* }\end{array}$ & $\begin{array}{c}2006- \\
2010 \\
\end{array}$ & $\begin{array}{c}2001- \\
2005\end{array}$ & $\begin{array}{l}1996- \\
2000\end{array}$ & $\begin{array}{c}1991- \\
1995 \\
\end{array}$ & $\begin{array}{c}1986- \\
1990 \\
\end{array}$ & $\begin{array}{c}1981- \\
1985 \\
\end{array}$ & $\begin{array}{c}\text { All time } \\
\text { total }\end{array}$ \\
\hline USA & 29,288 & 24,129 & 16,368 & 12,528 & 6,306 & 3,399 & 2,720 & 98,838 \\
\hline China & 23,064 & 9,385 & 2,491 & 943 & 348 & 252 & 122 & 36,721 \\
\hline Germany & 9,404 & 7,146 & 5,091 & 3,259 & 1,119 & 575 & 358 & 27,462 \\
\hline United Kingdom & 7,088 & 5,447 & 4,047 & 2,140 & 940 & 490 & 281 & 20,975 \\
\hline Japan & 6,895 & 5,477 & 3,705 & 2,257 & 894 & 523 & 433 & 20,738 \\
\hline
\end{tabular}

Table 4. Top 10 Arab Countries in Terms of their Attribution in Articles Related to "Solar" on Scopus Database

\begin{tabular}{lcccccccc}
\hline Country & $\begin{array}{c}2011- \\
\text { Present* }\end{array}$ & $2006-$ & $2001-$ & $1996-$ & $1991-$ & $1986-$ & $\begin{array}{c}1981- \\
1985\end{array}$ & $\begin{array}{c}\text { All time } \\
\text { total }\end{array}$ \\
\hline Saudi Arabia & 8,265 & 5,658 & 4,115 & 2,232 & 1,057 & 566 & 308 & 1,820 \\
Egypt & 768 & 341 & 218 & 192 & 115 & 101 & 31 & 1,766 \\
Algeria & 728 & 258 & 92 & 39 & 9 & 5 & 1 & 1,132 \\
Tunisia & 454 & 182 & 98 & 35 & 15 & 3 & 4 & 791 \\
Jordan & 188 & 113 & 66 & 63 & 43 & 27 & 0 & 507 \\
UAE & 375 & 110 & 19 & 18 & 16 & 6 & 4 & 501 \\
Iraq & 164 & 29 & 16 & 20 & 22 & 52 & 7 & 310 \\
Kuwait & 59 & 53 & 26 & 39 & 20 & 20 & 15 & 232 \\
Oman & 110 & 51 & 39 & 12 & 3 & 0 & 0 & 215 \\
Qatar & 139 & 41 & 6 & 2 & 2 & 7 & 1 & 198 \\
\hline
\end{tabular}




\section{Conclusion}

This paper presented the solar energy research situation in the UAE using Scopus-database. The UAE must rely less on oil and gas and needs to consider other sources of energy for power production such solar energy. Many researchers worked on various applications of solar energy for electricity production, water desalination, space cooling, etc.

The work [resented here can be used by researchers, politicians, industry, or decision makers to see how well the UAE has done in terms of investing in the field of solar energy and how it compares to other countries in the GCC, Arab world, and worldwide. It presented and identified up to date active institutions and researchers in the field of solar energy within the UAE using the data collected by Scopus. The progress of solar energy research in the UAE tells us that Masdar Institute of Science and Technology at Abu Dhabi is the most active institution in solar energy work in the UAE.

\section{References}

[1] A.A. El-Sebaii, F.S. Al-Hazmi, A.A Al-Ghamdi, global, direct and diffuse solar radiation on horizontal and tilted surfaces in Jeddah, Saudi Arabia

[2] Abdalla YAG, Baghdady MK. Global and diffuse solar radiation in Doha (Qatar). Solar and Wind Technology 1985;2(3/4):209-12.

[3] Khalil A, Alnajjar A. Experimental and theoretical investigation of global and diffuse solar radiation in the United Arab Emirates. Renewable Energy 1995;6(5-6):537-43.

[4] Measurement of solar-energy (direct beam radiation) in Abu Dhabi, UAE M.D. Islam , A.A. Alili, I. Kubo, M. Ohadi.K. Elissa, "Title of paper if known," unpublished.

[5] Imen Jeridi Bachellerie. Renewable energy in the GCC countries - resources, potential, and prospects. Gulf Research Center; 2012.
[6] Probability distributions of wind speed in the UAE T.B.M.J. Ouardaa, , C. Charrona, J.-Y. Shina, P.R. Marpua, A.H. Al-Mandoosc, M.H. Al-Tamimic, H. Ghediraa, T.N. Al Hosaryc.

[7] Sustainability in the Middle East: achievements and challenges Nivine Issa Sustainability Consultant and Saeed Al Abbar Director AESG, Dubai, United Arab Emirates.

[8] Developing a green building assessment tool for developing countries - Case of Jordan Hikmat H. Ali a, Saba F. Al Nsairat.

[9] Performance evaluation of solar insulation materials in UAE conditions Rajesh Reddy and Hamid Kayal.

[10] H.Radhi, "Can envelop codes reduce electricity and $\mathrm{CO} 2$ emissions in different types of buildings in the hot climate of Bahrain?," Energy, vol. 34, pp. 205$215,2009$.

[11] Prospect of Stand-Alone PV-Diesel Hybrid Power System for Rural Electrification in UAE Mutasim Nour, Golbarg Rohani.

[12] Design and Implementation of $59 \mathrm{KWp}$ Solar Hybrid Mini-Grid in SOLAB, Ras Al Khaimah Zaki Iqbal, Gorkem Soyumer, Waqarullah Kazim.

[13] Sustainable System Solutions: RAK Research and Innovation Center, Mousa Mohsen, Zaki Iqbal, Uday Kumar, Waqar Ullah, Omar Akash, Int. J. of Sustainable Water \& Environmental Systems, Vol. 5 (2013) 67-76.

[14] Hussain, H.J. Development of a hybrid powerplant for Kuwait: The simultaneous production of power, fresh water and cooling, Doctoral thesis, Cranfield University, United Kingdom, March 2010.

[15] Picinardi, A. Cogeneration of cooling energy and fresh water. Doctoral Thesis, University of Bergamo, Italy, 2011.

[16] Calise, F.; d'Accadia, M.D.; Piacentino, A. A novel solar trigeneration system integrating PVT (photovoltaic/thermal collectors) and SW (Seawater) desalination: Dynamic simulation and economic assessment. Energy 2014, 67, 129-148. 